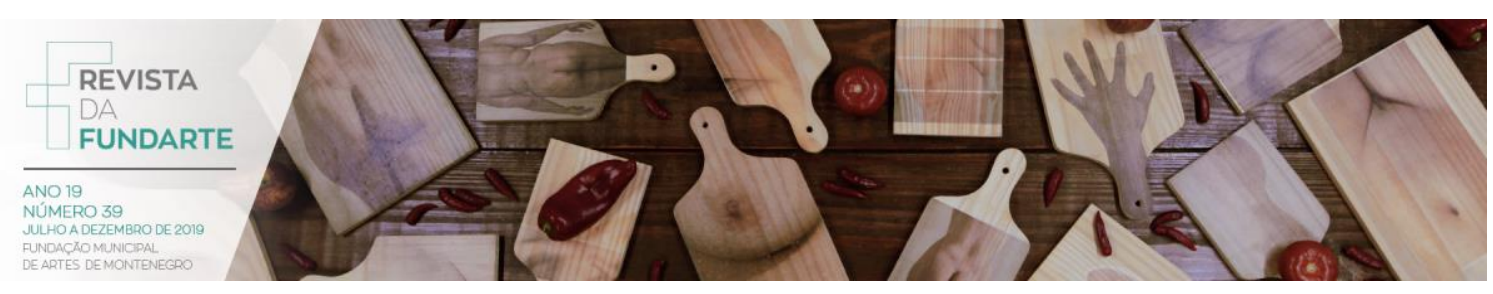

\title{
EU, PROFESSOR DE TEATRO PARA CRIANÇAS PEQUENAS? RELATO DE UMA EXPERIÊNCIA VIVIDA COMO ESTAGIÁRIO NO CURSO DE TEATRO-LICENCIATURA
}

Felipe Cremonini de Leon Andrisa Kemel Zanella da FUNDARTE, Montenegro, p.209-221, ano 19, no 39, julho/dezembro de 2019.

Disponível em: http://.seer.fundarte.rs.gov.br/index.php/RevistadaFundarte/index $>20$ de dezembro de 2019. 


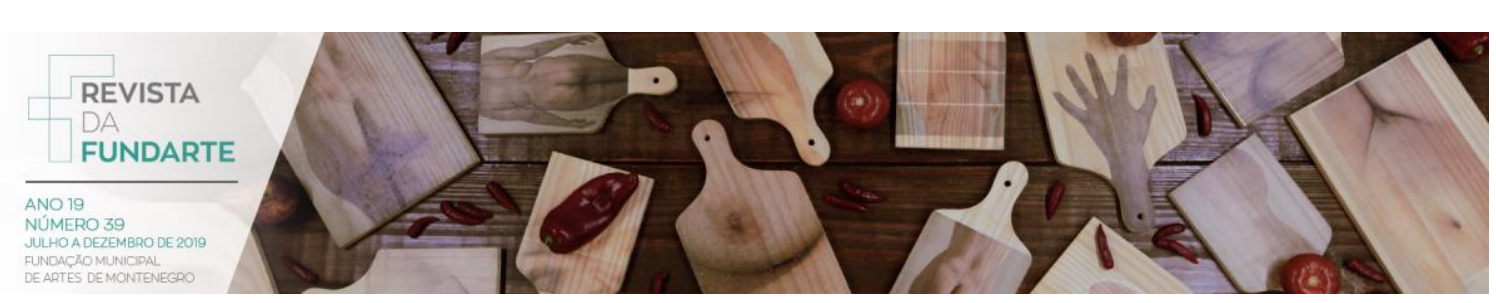

\title{
EU, PROFESSOR DE TEATRO PARA CRIANÇAS PEQUENAS? RELATO DE UMA EXPERIÊNCIA VIVIDA COMO ESTAGIÁRIO NO CURSO DE TEATRO-LICENCIATURA
}

Felipe Cremonini de Leon ${ }^{1}$ Andrisa Kemel Zanella²

\begin{abstract}
Resumo: Este trabalho busca relatar a experiência vivida na Educação Infantil em uma escola pública do município de Pelotas/RS, problematizando os desafios e as surpresas da experiência de inserção como professor de teatro para crianças pequenas. O trabalho, realizado durante o Estágio I Educação Infantil ou Ensino Fundamental, no Curso de Teatro - Licenciatura da UFPel, englobou a contação de histórias, brincadeiras tradicionais e jogos teatrais. Como aprendizado resultante dessa experiência, para os alunos foi o fato de poderem compreender o que era teatro e reconhecer seus personagens, figurinos, cenários e conceitos de ator/atriz e autor/autora. E para o estagiário, 0 aprendizado foi se desarmar da academia e suas rígidas regras e prazos e reaprender a fazer teatro de forma mais espontânea, livre de justificativas poéticas e trabalhar com o corpo e sua humanidade, transformando isso em arte e educação.
\end{abstract}

Palavras-Chave: Relato de experiência; Estágio em educação infantil; Teatro.

\section{ME, THEATER TEACHER FOR SMALL CHILDREN? AN EXPERIENCE LIVED AS A INTERN IN THE COURSE OF THEATER-DEGREE}

\begin{abstract}
This work search to give visibility to the experience lived in Early Childhood Education in a public school in the city of Pelotas/RS, problematizing the challenges and surprises of the insertion experience as a theater teacher for small children. The work, accomplished during Apprenticeship I Early Childhood Education or Elementary School, in the course of Theater - Degree of UFPel, included the storytelling, traditional games and theatrical games. As learning resulting from this experience, for the students it was the fact that they were able to understand what theater was and recognize their characters, costumes, scenarios and concepts of actor/actress and author. And for the intern, the learning was to leave aside a rigid posture based on rigid rules and deadlines and to learn again to do theater in a more spontaneous way, free from poetic justifications and to work with the body and its humanity, transforming it into art and education.
\end{abstract}

Keywords: Experience; Theater; Apprenticeship in early childhood education.

\footnotetext{
${ }^{1}$ Graduando no curso de Teatro Licenciatura da Universidade Federal de Pelotas (UFPel), Em 2016 foi bolsista do projeto Teatro do Oprimido na Comunidade (TOCO). Em 2017 foi bolsista do Programa Institucional de Bolsas de Iniciação a Docência (PIBID Teatro). Em 2017 foi preparador de elenco e ator do curta-metragem integrante da Seleção Oficial da $45^{\text {a }}$ edição do Festival de Cinema de Gramado.

2 Doutora em Educação pelo Programa de Pós-Graduação em Educação da Universidade Federal de Pelotas, com período sanduíche na Universidade Fernando Pessoa, Porto/Portugal. Mestre em Educação pelo Programa de Pós-Graduação em Educação da Universidade Federal de Santa Maria. Pedagoga pela Universidade Luterana do Brasil/Canoas/RS. Bacharel em Artes Cênicas nas habilitações Interpretação e Direção Teatral pela Universidade Federal de Santa Maria/RS.
}

LEON, Felipe Cremonini de; ZANELLA, Andrisa Kemel. Eu, professor de teatro para crianças pequenas? Relato de uma experiência vivida como estagiário no curso de teatro-licenciatura. Revista da FUNDARTE, Montenegro, p.209-221, ano 19, no 39, julho/dezembro de 2019.

Disponível em: http://.seer.fundarte.rs.gov.br/index.php/RevistadaFundarte/index> 20 de dezembro de 2019. 


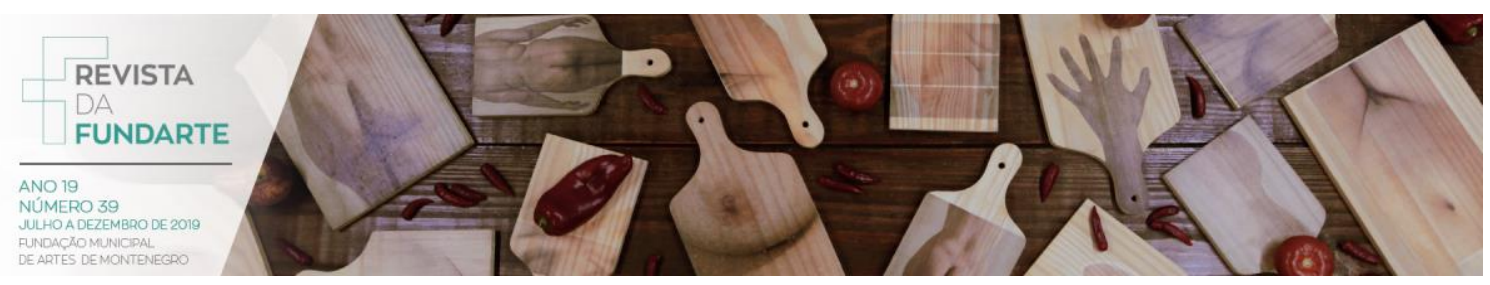

Teatro, docência, crianças: considerações iniciais

Esta escrita tem por objetivo relatar a experiência vivida na Educação Infantil em uma escola pública do município de Pelotas/RS, problematizando os desafios e as surpresas da experiência de inserção como professor de teatro para crianças pequenas. A prática que será apresentada teve como proposta a introdução da linguagem teatral ${ }^{3}$ no contexto da pré-escola, em uma turma com 20 alunos, na faixa etária de 05 e 06 anos. O trabalho desenvolvido englobou as atividades de contação de histórias, brincadeiras tradicionais e jogos teatrais, realizadas durante o Estágio I - Educação Infantil ou Ensino Fundamental, no Curso de Teatro - Licenciatura da UFPel, no $2^{\circ}$ semestre de $2017^{4}$.

O ensino do teatro, assim como as demais áreas das artes cênicas, traz consigo uma importância não apenas social, como também de autoconhecimento do indivíduo e ainda promove o aspecto lúdico tão importante na infância, como será visto nas seções a seguir. Assim, apresenta-se nas próximas páginas o trabalho desenvolvido e o contexto vivido, uma reflexão crítica acerca do teatro com crianças pequenas, finalizando com uma escrita sobre como a experiência vivida contribuiu em minha formação.

\section{E agora? A construção de uma proposta de trabalho}

Anteriormente as disciplinas de estágio, que começam a partir do sexto semestre do curso de Teatro Licenciatura, nós acadêmicos, cursamos quatro disciplinas de Pedagogia do Teatro, momento que conhecemos as diferentes metodologias de ensino do teatro, construindo um referencial teórico e também prático sobre as formas e a importância da inserção do teatro na educação. Mesmo com este repertório, a disciplina de estágio na universidade já começa frenética: é preciso rapidamente encontrar escolas que possuam interesse em receber estagiários do teatro, entrar em contato com elas, enviar os documentos necessários para os órgãos que devem liberar o estágio e, no meio de tudo isso, elaborar um

\footnotetext{
${ }^{3}$ A escola em que foi desenvolvida a prática de estágio foi inaugurada no ano de 2016 e até então não havia tido aulas de teatro no cotidiano das crianças, embora o teatro sempre esteve presente nesse contexto (será falado sobre isto abaixo).

${ }^{4} \mathrm{O}$ estágio foi realizado em dupla, com um colega de curso, e teve como orientadora Professora Andrisa Kemel Zanella coautora do presente artigo.
}

LEON, Felipe Cremonini de; ZANELLA, Andrisa Kemel. Eu, professor de teatro para crianças pequenas? Relato de uma experiência vivida como estagiário no curso de teatro-licenciatura. Revista da FUNDARTE, Montenegro, p.209-221, ano 19, oㅜ 39, julho/dezembro de 2019.

Disponível em: http://.seer.fundarte.rs.gov.br/index.php/RevistadaFundarte/index $>20$ de dezembro de 2019. 


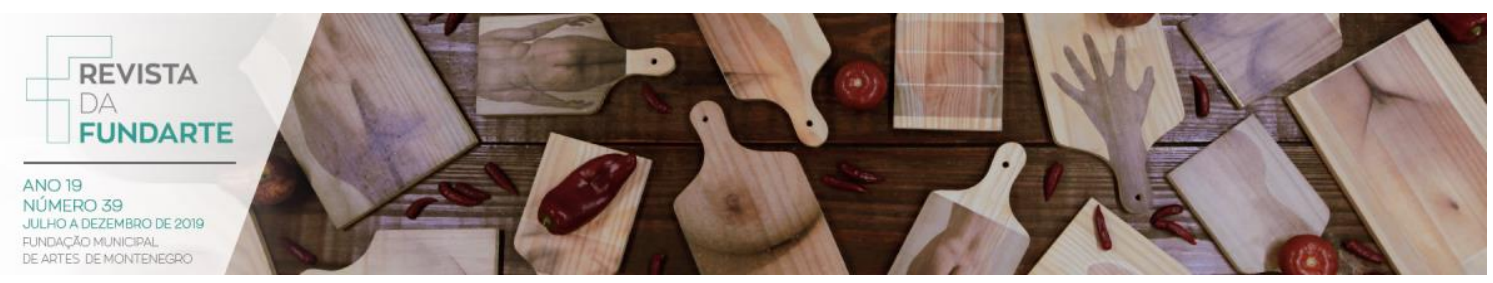

plano de ensino e os primeiros planos de aula, garantindo que o estágio inicie a tempo hábil para acontecerem as observações. pré-estágio e aulas, finalizando o estágio com a carga horária exigida pela instituição. Neste processo, existe uma grande expectativa em elaborar um estágio que seja interessante e com um bom desenvolvimento, pois é nesse momento que se dá a inserção no campo profissional de atuação antes de formados.

A primeira disciplina de estágio no curso de Teatro acontece em duplas, portanto realizei o estágio com um colega, mas neste documento optei por relatar a minha experiência em primeira pessoa. Desde minha primeira inserção na escola uma Escola central da Cidade de Pelotas, no sul do Brasil - a ideia do estágio era trabalhar com contos infantis e resgatar brincadeiras tradicionais da infância, utilizando os jogos teatrais. Justifico esta escolha, baseado no que aponta Souza (2008), em seu livro "Um palco para o conto de fadas". Ele diz que:

O conto de fadas ajuda a criança a conhecer a história, muitas vezes oculta, da constituição das relações sociais do mundo, tal como o conhecemos hoje, assim como as diferentes maneiras pelas quais a humanidade age neste mundo, na eterna luta pela vida, construindo sociedades e as destruindo, estabelecendo sistemas de governo e estilos de vida. (SOUZA, 2008, p. 17).

As motivações para a realização desta proposta partiram da necessidade de se trabalhar com uma linguagem comum para a idade da turma e da vontade de trazer para aquela geração os contos e histórias que eu cresci ouvindo, partindo do princípio de que, como afirma o autor acima citado, "a narrativa fantasiosa está profundamente relacionada com o passado da humanidade" (SOUZA, 2008, p. 18). Penso que a partir dos jogos infantis, que aprendi no decorrer de minha história, eu poderia proporcionar uma experiência parecida a uma nova geração, repassando uma tradição e a partir daí, introduzir o teatro através dos jogos teatrais e brincadeiras infantis.

A autora Ângela Barcelos Café exemplifica em seu artigo "O contador de Histórias no Ensino de Teatro" que, "por meio de ações e jogos lúdicos, a proposta é fazer das aulas de arte um ambiente acolhedor, instigante e criativo, para que os alunos possam se experimentar como narradores e como ouvintes de histórias"

LEON, Felipe Cremonini de; ZANELLA, Andrisa Kemel. Eu, professor de teatro para crianças pequenas? Relato de uma experiência vivida como estagiário no curso de teatro-licenciatura. Revista da FUNDARTE, Montenegro, p.209-221, ano 19, no 39, julho/dezembro de 2019.

Disponível em: http://.seer.fundarte.rs.gov.br/index.php/RevistadaFundarte/index> 20 de dezembro de 2019. 


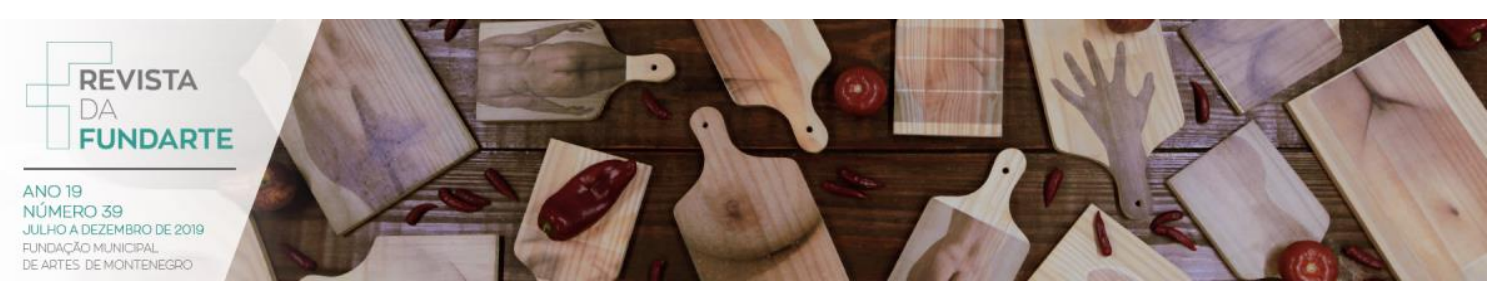

(CAFÉ, 2016, p. 303). E foi esse ambiente que tentei propiciar a cada nova aula, fazendo com que os alunos pudessem se sentir membros ativos durante a vivência teatral.

O objetivo geral da proposta teatral para as crianças da Educação Infantil, parte do documento de plano de ensino elaborado e entregue antes do começo da prática de estágio. Contemplava instigar o contato com jogos teatrais e dramáticos e a contação de histórias infantis com dramatização, introduzindo o teatro para a turma. E de forma específica: propiciar o brincar instigando a espontaneidade; explorar a expressividade corporal, a partir de jogos teatrais; entrar em contato com aspectos primários de interpretação a partir da dramatização dos contos a serem trabalhados; trabalhar a recepção teatral e fruição artística, através de contação de histórias e peças teatrais; e estimular o senso de coletividade.

Assim, busquei nos contos tradicionais de Hans Andersen e dos Irmãos Grimm ${ }^{5}$ e em minha bagagem alguns jogos do fichário de Viola Spolin ${ }^{6}$, para efetivar a proposta de ensino de teatro para crianças na educação infantil.

\section{Conhecendo-me como professor: a prática de estágio}

A escola já possuía um contato prévio com a linguagem teatral, pelo fato de que quinzenalmente eles faziam apresentações de teatro com as turmas para os familiares e colegas - tudo transmitido ao vivo pelo Facebook, resultado normalmente de uma grande vontade do corpo docente, que nem sempre tinha algum tipo de formação em teatro, o que resultou em algumas crianças que não sabiam muito bem o que havia sido feito, ou não imaginavam outras possibilidades de fazer teatro. O prédio era equipado com uma ótima infraestrutura de sala de jogos, biblioteca, sala de vídeos, pátios internos e externos, além de um palco de

\footnotetext{
${ }^{5}$ Os contos utilizados foram "O Soldadinho de Chumbo" de Hans Andersen e havia planejado utilizar "João e Maria" dos Irmãos Grimm, que acabou sendo substituído pela versão infantil de "Romeu e Julieta" de Shakespeare, tendo em vista que seria interessante trabalhar uma história clássica teatral. 6 Viola Spolin (1906 - 1994) foi uma diretora e autora estadunidense, sistematizadora dos Jogos Teatrais e grande influenciadora do teatro improvisacional contemporâneo. Alguns dos jogos do fichário de Viola Spolin utilizados foram: Pegador com Explosão, Pegar e Congelar, Três mocinhos na Europa, Quem iniciou o movimento? Dar e Tomar e Corrida de Índios, pois considerei que seriam propícios para estimular a memória corporal, a precisão de movimento, a expressividade e diversos outros estímulos que são necessários para o trabalho a ser desenvolvido no estágio.
}

LEON, Felipe Cremonini de; ZANELLA, Andrisa Kemel. Eu, professor de teatro para crianças pequenas? Relato de uma experiência vivida como estagiário no curso de teatro-licenciatura. Revista da FUNDARTE, Montenegro, p.209-221, ano 19, no 39, julho/dezembro de 2019.

Disponível em: http://.seer.fundarte.rs.gov.br/index.php/RevistadaFundarte/index $>20$ de dezembro de 2019. 


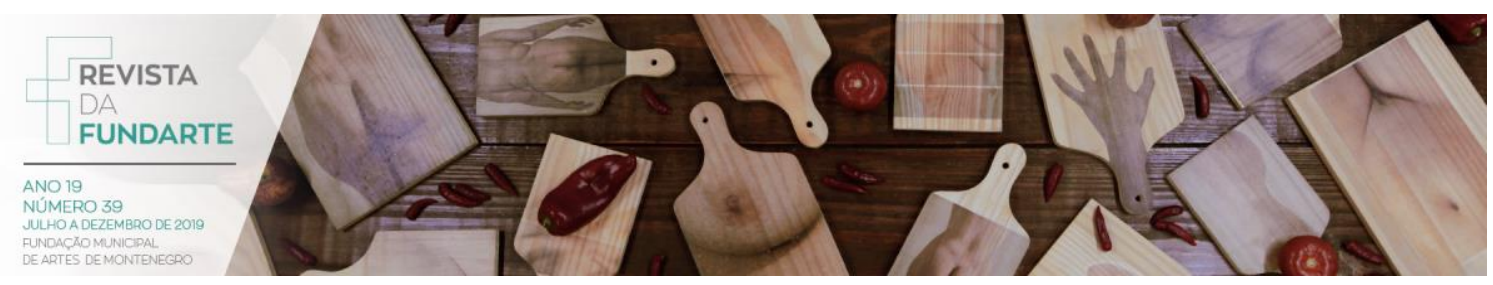

teatro localizado no pátio interno, que dá acesso a todas as salas de aula (Ver figura 1).

A partir das observações feitas antes de iniciar a docência, pude perceber uma grande predisposição para os jogos com regras e as brincadeiras "guiadas", pois o espaço da escola auxiliava na execução desses jogos. As crianças tendiam a obedecer a um "mestre", como pude ver na aula de judô oferecida pela escola, onde o ministrante da aula pedia para ser chamado dessa forma (mestre) e exigia uma postura extremamente madura em relação a essa arte marcial. $O$ fato de exigir tal postura de crianças que possuíam no máximo seis anos me causou desconforto e me instigou ainda mais a experimentar com eles possibilidades de jogos e brincadeiras a partir de histórias que eu esperava que fossem atrativas para elas.

Os primeiros dias de aula foram os mais caóticos, eu e meu colega evitávamos usar nossa "autoridade" como professores para exigir algum tipo de concentração ou organização nas aulas. Fui compreendendo aos poucos como a figura do professor em sala de aula funciona e como ministrar atividades sendo o mediador dos encontros.

O maior desafio neste sentido era colocar em prática tudo que eu acreditava que a docência

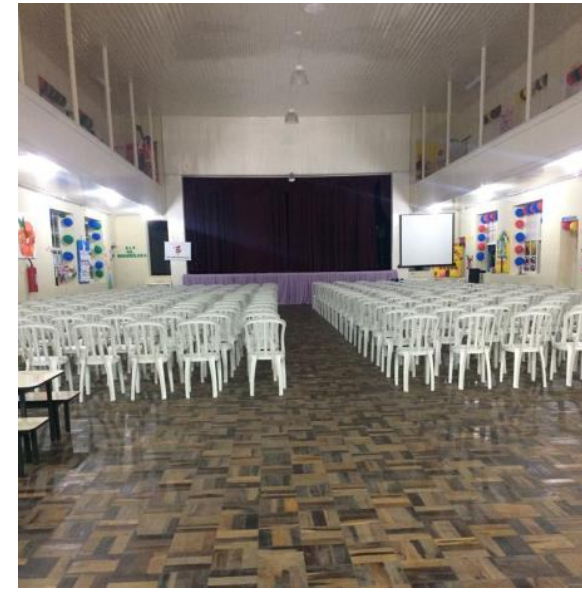

Figura 1- Interior da escola organizado para uma apresentação, onde é possível ver o palco e as portas das salas de aula. representava: horizontalidade hierárquica, professor como articulador de conhecimento e não como detentor do mesmo e tudo que foi possível construir de autoimagem de professor durante os semestres de preparação para o estágio. Tudo isso foi por água abaixo em meio aos protestos das crianças que não queriam jogar, cansavam das brincadeiras rapidamente ou simplesmente se recusavam a tentar. Foi um exercício, não de se redescobrir enquanto docente, porque eu nunca havia experenciado essa posição, mas sim de autoconhecimento como profissional.

Durante as aulas de estágio foi trabalhado, primeiramente, conceitos ligados à linguagem teatral, como palco, plateia, figurino, cenário, ator/atriz, o que foi da FUNDARTE, Montenegro, p.209-221, ano 19, ํo 39, julho/dezembro de 2019.

Disponível em: http://.seer.fundarte.rs.gov.br/index.php/RevistadaFundarte/index $>20$ de dezembro de 2019. 


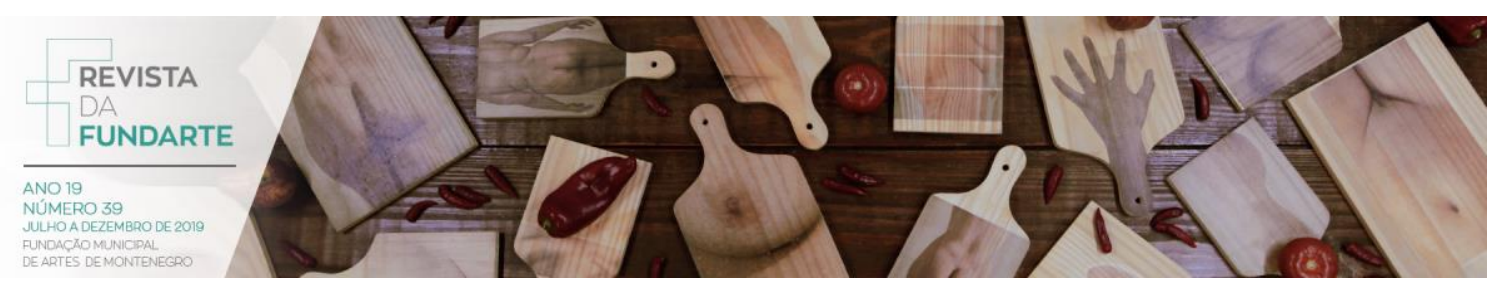

relativamente fácil pelo fato dos alunos já terem participado de algumas das apresentações quinzenais que protagonizaram na escola. A referência, neste momento, foi o "Dicionário do Teatro" de Patrice Pavis (2015), tudo isso como preparação prévia para as contações de histórias que viriam em sequência no cronograma do plano de ensino.

Os jogos teatrais foram trabalhados em uma crescente, começando com a reprodução de brincadeiras tradicionais solicitada por eles, como "passa o anel", "seu mestre mandou" e "pega-pega"7, introduzindo aos poucos elementos lúdicos e teatrais, como um pega-pega que foge de um monstro inserindo a interpretação, um seu mestre mandou, que tem como base o corpo de um personagem pertencente à alguma história, até trabalhar diretamente com os jogos de Viola Spolin. Percebi nos primeiros encontros, que era preciso participar inicialmente dos jogos junto com os alunos, porque isso facilitaria a visualização das regras que eles possuíam e estimularia a participação, como observa Ingrid Koudela, no texto "A ida ao Teatro", refletindo sobre os Jogos Teatrais em escolas. Para a autora, na prática com jogos teatrais,

\begin{abstract}
é possível desenvolver liberdade dentro de regras estabelecidas. O material do teatro, gestos e atitudes é experimentado concretamente no jogo, sendo que a conquista gradativa de expressão física nasce da relação estabelecida com a sensorialidade. (KOUDELA, s./d., p. 35).
\end{abstract}

Nos primeiros jogos, tentei ser uma figura externa que "dava as regras", o que percebi de imediato que não funcionou, pois poucas crianças realmente deram atenção. Quando estava na reta final do estágio e já havia cumprido grande parte do que propus no plano de ensino decidi, juntamente com meu colega, retomar os jogos que não haviam "funcionado" no primeiro momento do estágio, dessa vez me colocando como jogador e mediador de fato, e o resultado foi muito mais satisfatório do que a primeira experiência.

\footnotetext{
7 Passa o anel - a brincadeira consiste em organizar os jogadores em roda, ou em fila, onde ficam com as mãos fechadas com uma breve abertura, por onde o jogador com o anel irá passar as suas mãos; outro jogador, previamente selecionado, deve adivinhar com quem está o anel. Seu mestre mandou - um dos jogadores selecionado pelo grupo, o mestre, dá instruções aos demais acompanhado da frase "Seu mestre mandou"; aquele que não conseguir cumprir a "ordem" fica fora da rodada. Pega-pega - brincadeira onde o grupo deve fugir do pegador; quando um jogador é pego, este passa a ser o novo pegador.
}

LEON, Felipe Cremonini de; ZANELLA, Andrisa Kemel. Eu, professor de teatro para crianças pequenas? Relato de uma experiência vivida como estagiário no curso de teatro-licenciatura. Revista da FUNDARTE, Montenegro, p.209-221, ano 19, oㅡ 39, julho/dezembro de 2019.

Disponível em: http://.seer.fundarte.rs.gov.br/index.php/RevistadaFundarte/index> 20 de dezembro de 2019. 


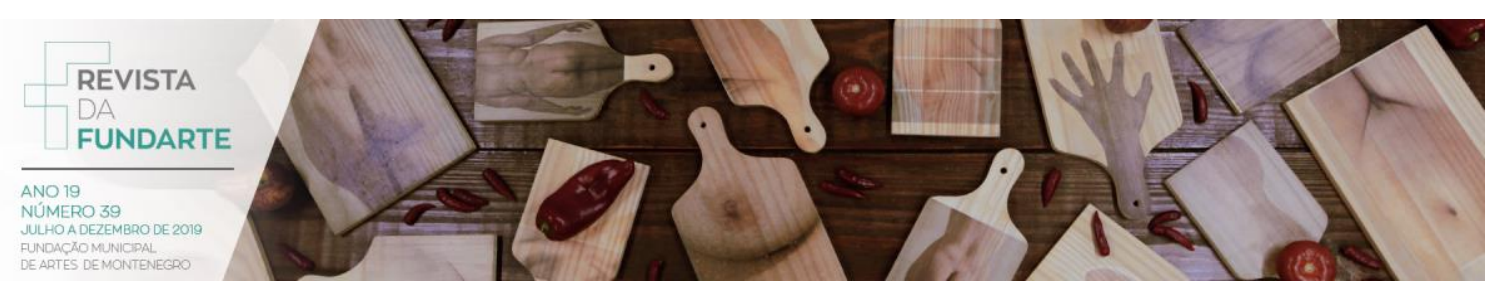

$\mathrm{Na}$ introdução do livro "Jogar, Representar", Jean-Pierre Ryngaert (2009) enfatiza a importância do jogo teatral para todos e não somente para atores, a fim de "delimitar a relação do jogo como motor e de tirar proveito disso para os diferentes setores que nos interessam" (RYNGAERT, 2009, p. 23). E, ainda, Taís Ferreira reforça, em seu artigo "A Pedagogia do Teatro e a Recepção Teatral Podem Caminhar Juntas?", a importância da presença do teatro na educação, "tanto pelos possíveis benefícios trazidos pela sociabilidade como pela visibilidade que os grupos teatrais trazem às instituições junto à comunidade" (FERREIRA, 2010, p. 114). Tudo isso para evidenciar a importância do trabalho, enquanto arte-educador, e articular teatro na escola.

Em relação à contação de histórias, o primeiro conto trabalhado foi "O Soldadinho de Chumbo", de Hans Andersen. Aqui percebo a falta de preparo ao utilizar um livro de fachada para criar uma ilusão, com folhas de ofício escondidas contendo a história impressa, e não um livro de contos de fato o que pode ter prejudicado um pouco a experiência da contação, já que as crianças demonstraram grande curiosidade em ver as páginas do que estava sendo lido. Apesar disso, o resultado foi positivo e isso refletiu nas atividades de desenho que elas realizaram na aula seguinte ao conto, em que todas estavam com a história muito presente, como se eu houvesse acabado de contar. No segundo conto, abandonei a ideia presente no plano de ensino de trabalhar com "João e Maria" para abraçar o livro infantil das peças de Shakespeare e apresentar às crianças "Romeu e Julieta". Assim pude levar o livro e mostrar as ilustrações para os alunos, apresentando-Ihes uma importante referência teatral. Trabalhei a peça a partir dos conhecimentos já construídos com a turma, investindo na criação de passagens favoritas da história por meio do exercício de intepretação.

A criação de desenhos sobre as histórias contadas foi um recurso muito utilizado. Embora essa prática seja tão cotidiana na vida das crianças, busquei no decorrer das aulas ressignificá-las com provocações, como utilizar materiais alternativos para o desenho (galhos, folhas, sementes, glitter) e desenhar em dupla.

Para que o trabalho também pudesse ser corporal, trabalhei com jogos que exploravam a interpretação dos personagens das histórias, instigando a imaginação

LEON, Felipe Cremonini de; ZANELLA, Andrisa Kemel. Eu, professor de teatro para crianças pequenas? Relato de uma experiência vivida como estagiário no curso de teatro-licenciatura. Revista da FUNDARTE, Montenegro, p.209-221, ano 19, oㅡ 39, julho/dezembro de 2019.

Disponível em: http://.seer.fundarte.rs.gov.br/index.php/RevistadaFundarte/index $>20$ de dezembro de 2019. 


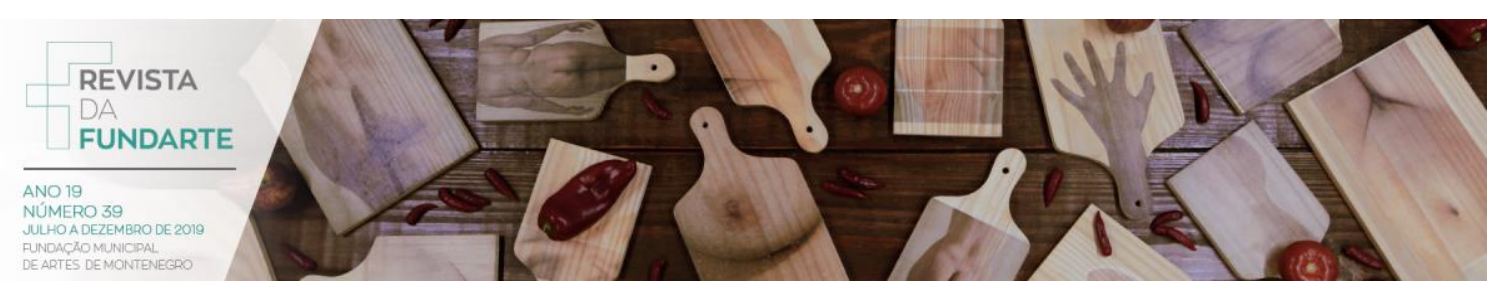

e o universo do faz de conta em sala de aula. Assim, as crianças corporificavam os personagens, recriando cenas - como já citado, ou imaginando o corpo e jeito de andar de um personagem. Ainda dividimos a turma em grupos de personagens favoritos que se repetiam, e fizemos brincadeiras com cada grupo, interpretando determinado personagem à sua maneira.

No sentido de vivenciar a linguagem teatral, a partir de uma abordagem triangular (contextualização histórica, fazer artístico e apreciação teatral) (BARBOSA, 2003), os alunos assistiram uma peça infantil de um colega do curso que circulou em todas as escolas onde tinha acadêmicos da turma de estágio da UFPel, além de assistirem a encenação de "O Mágico de Oz", encenada por estudantes de outra escola de Educação Infantil e organizada por outra dupla de estagiários do teatro presentes na escola. Dentre tudo isso, vale destacar a dramatização, a partir dos contos que se dava após as leituras, e trazia uma grande espontaneidade e vontade dos alunos de representarem alguns dos personagens das histórias.

Entre os desafios enfrentados durante o estágio, tive várias atividades da escola que envolveram os alunos das quais não fui informado e, portanto, não pude realizar as aulas, além de alguns problemas de conflitos entre os alunos. Mas o principal desafio foi, provavelmente, trabalhar com jogos e exercícios teatrais e fazêlos compreender como aquilo era teatro.

\section{Os desafios e as surpresas de ser professor de teatro na Educação Infantil}

A partir de tudo que relatei, é possível perceber que consegui cumprir grande parte do que havia sido planejado previamente, porém "estimular o senso de coletividade" foi um dos maiores desafios a cumprir do plano de ensino e, talvez um dos maiores equívocos quando pensei as aulas, já que não imaginava trabalhar a importância que isso tem no contexto da educação infantil. Depois de refletir sobre, penso que seria muito impositivo de minha parte querer promover uma prática significativa sem antes permitir que eles compreendessem porque o senso de coletividade era importante. Penso que o objetivo deveria ter sido estimular 0 respeito, para que a partir daí a coletividade pudesse ser trabalhada.

LEON, Felipe Cremonini de; ZANELLA, Andrisa Kemel. Eu, professor de teatro para crianças pequenas? Relato de uma experiência vivida como estagiário no curso de teatro-licenciatura. Revista da FUNDARTE, Montenegro, p.209-221, ano 19, oㅜ 39, julho/dezembro de 2019.

Disponível em: http://.seer.fundarte.rs.gov.br/index.php/RevistadaFundarte/index 20 de dezembro de 2019. 


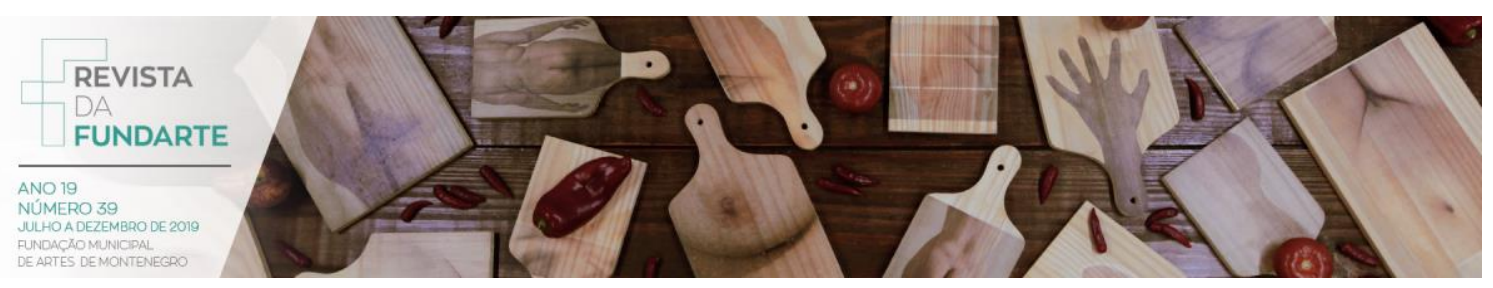

A autora Souza (2008) relata uma experiência realizada em uma escola de Educação Infantil, em que buscou a partir de exercícios de expressão corporal estimular o respeito, "exercitando a afetividade, o inter-relacionamento, a sensibilização, enfatizando a importância do respeito ao limite de cada indivíduo dentro de uma coletividade" (SOUZA, 2008, p. 43), mostrando como o respeito ao outro é a base para compreender a importância do coletivo.

$\mathrm{Na}$ primeira aula, em uma atividade inicial que possibilitaria conhecê-los e eles a mim, houve resistência quanto a algumas duplas que tentei formar, e piadinhas quando algum colega "alvo" tinha um momento de protagonismo. Isso me surpreendeu, pois cheguei ao estágio acreditando que as crianças pequenas não teriam problemas em trabalhar com os colegas. Percebi que era a base do respeito que estava faltando ali.

O autor acima citado sugere possibilidades de trabalhar personagens, como o Anão e o Gigante, em diversos tipos de exercícios teatrais de interação que estimulam o respeito em relação ao outro:

Em que as vivências estimuladas pelo exercício de jogos de expressão corporal e teatral levam em conta o olhar do outro, o contato, o afeto, as significações construídas em coletividade, a possibilidade de acabamento implícita no convívio. (SOUZA, 2008, p. 45).

Acredito que trabalhar o respeito e, posteriormente, trabalhar o senso de coletividade teria sido possível durante as contações de história, se o foco tivesse sido esse desde o começo, ou pelo menos propor isso durante as mediações posteriores. Pois, como afirma Café (2016), é possível fazer diversas interpretações de uma contação de histórias e trabalhar com elas:

Não importa quem, não importa como, esses narradores são pessoas que provocam imagens e emoções múltiplas em seus ouvintes, que encontram espaço para sua vivência no mundo da fantasia, que é diferente da realidade em que vivemos todos os dias. (CAFÉ, 2016, p. 306).

Hoje, após a prática de estágio, reflito que se tivesse apostado mais fortemente na contação de histórias, isso, facilitaria a ideia de utilizar o próprio

LEON, Felipe Cremonini de; ZANELLA, Andrisa Kemel. Eu, professor de teatro para crianças pequenas? Relato de uma experiência vivida como estagiário no curso de teatro-licenciatura. Revista da FUNDARTE, Montenegro, p.209-221, ano 19, nํ39, julho/dezembro de 2019.

Disponível em: http://.seer.fundarte.rs.gov.br/index.php/RevistadaFundarte/index> 20 de dezembro de 2019. 


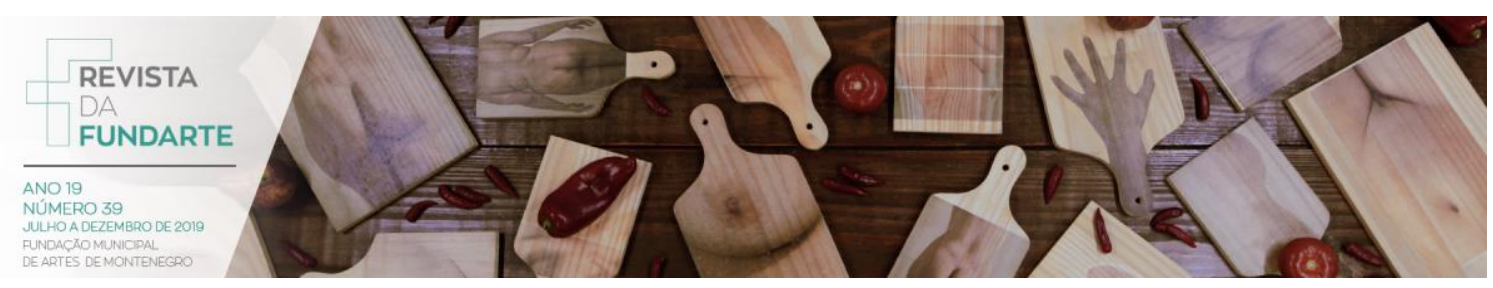

universo do conto para realizar um trabalho de conscientização sobre respeito e coletividade, enfatizando a ludicidade ao mesmo tempo.

\section{Eu professor! Considerações finais}

Apesar de todo o preparo para um estágio, é impossível ter a dimensão de um contexto de sala de aula até, efetivamente, estar lá na figura de professor. Claro, todo o estudo teórico realizado no decorrer do curso contribui para a formação, mas pouco quando se trata de compreender o planejamento de uma aula, as "cartas na manga", necessárias para os imprevistos e os desafios do cotidiano.

Não que eu culpe a mim ou a meu colega pelo que não foi possível atingir durante o estágio, pelo contrário, acredito que obtivemos um saldo final positivo ao proporcionarmos aos alunos uma iniciação à linguagem teatral. Porém, penso que a maior complicação aqui foi conseguir articular os conhecimentos em Teatro à prática de docência, não no sentido de ensinar teatro, mas sim de usar as potencialidades particulares vindas do teatro para melhorar o desempenho enquanto educador.

No teatro, lida-se muito com o humano, com o particular, com a psicologia de personagens e questões pessoais dos atores, memória afetiva e, enfim, tudo que puder auxiliar no trabalho enquanto artistas. Toda essa consciência parece que foi um pouco deixada de lado quando entrei na sala de aula, como se docência e vida artística fossem coisas totalmente distintas - e não são!

Trabalhar com esse "olhar artístico e poético" aprimorado na sala de aula, teria facilitado muito quando me deparei com situações quase comuns, quando se trabalha com crianças e perceber, sensivelmente, como lidar com o problema encontrado sobre respeito. Aprendi a não separar o "eu artista" do "eu professor", e consequentemente a diminuir a linha divisória que existia, para mim, entre as disciplinas de educação e as demais cadeiras do curso de teatro.

Durante o decorrer do estágio, acredito que o maior aprendizado deixado para os alunos foi a compreensão sobre as experiências que eles já haviam vivenciado na escola. É relativamente comum ver escolas que promovem anualmente a "peça de fim de ano" para os pais assistirem e, na maioria das vezes, os alunos não sabem o que, exatamente, está sendo trabalhado naqueles ensaios. Pude, então, ajudá-los a

LEON, Felipe Cremonini de; ZANELLA, Andrisa Kemel. Eu, professor de teatro para crianças pequenas? Relato de uma experiência vivida como estagiário no curso de teatro-licenciatura. Revista da FUNDARTE, Montenegro, p.209-221, ano 19, nº 39, julho/dezembro de 2019.

Disponível em: http://.seer.fundarte.rs.gov.br/index.php/RevistadaFundarte/index> 20 de dezembro de 2019. 


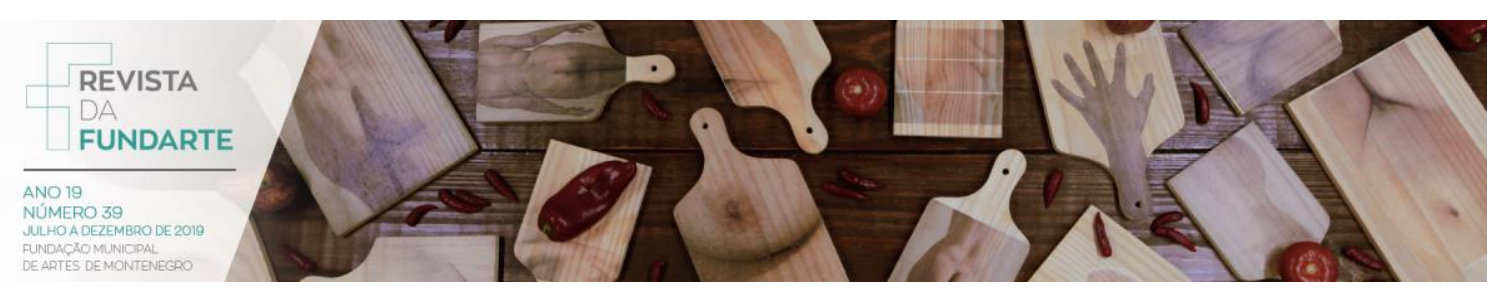

compreender como aquilo era teatro e reconhecer personagens, figurinos, cenários e até mesmo conceitos de ator/atriz e autor/autora de determinadas obra.

Também foi possível deixar como legado a reflexão de "o que é teatro", já que trabalhei leituras dramáticas e pude proporcionar a apreciação de um espetáculo com apenas um ator em cena - o que eles não sabiam que era possível. Dessa forma, ampliou-se a visão de teatro para além do que era vivenciado por eles na escola.

Já para mim, o aprendizado foi, primeiramente, o de me desarmar da academia e suas rígidas regras e prazos e, reaprender a fazer teatro de forma mais espontânea, livre de justificativas poéticas e trabalhar com o corpo e sua humanidade, transformando isso em arte e educação.

Além do que já era possível imaginar que aconteceria, como por exemplo, ter que "fugir" do plano de aula do dia para respeitar o processo e os rumos que a proposta trabalhada estava caminhando na sala de aula, bem como aprendi a importância do papel do professor na Educação Infantil. Percebi que as crianças viam o professor (os estagiários também) como uma figura de grande conhecimento e um ser inatingível. Com o teatro elas trabalharam lado a lado nos jogos, colocando-se como um ser na horizontalidade. Não tenho como dizer se os alunos puderam refletir sobre isso, mas com certeza é algo que os marcou de alguma forma.

Com o trabalho de estágio realizado, as crianças revisitaram a biblioteca da escola (que os mesmos falaram que não costumavam frequentar), sem contar os diversos retornos que recebi das próprias crianças dizendo o quanto era legal poder tirar as classes da sala e usá-la de outra forma, que não fosse apenas sentados nelas, o que reforçou ainda mais a importância do teatro na educação e a importância da minha presença ali.

LEON, Felipe Cremonini de; ZANELLA, Andrisa Kemel. Eu, professor de teatro para crianças pequenas? Relato de uma experiência vivida como estagiário no curso de teatro-licenciatura. Revista da FUNDARTE, Montenegro, p.209-221, ano 19, ํo 39, julho/dezembro de 2019.

Disponível em: http://.seer.fundarte.rs.gov.br/index.php/RevistadaFundarte/index $>20$ de dezembro de 2019. 


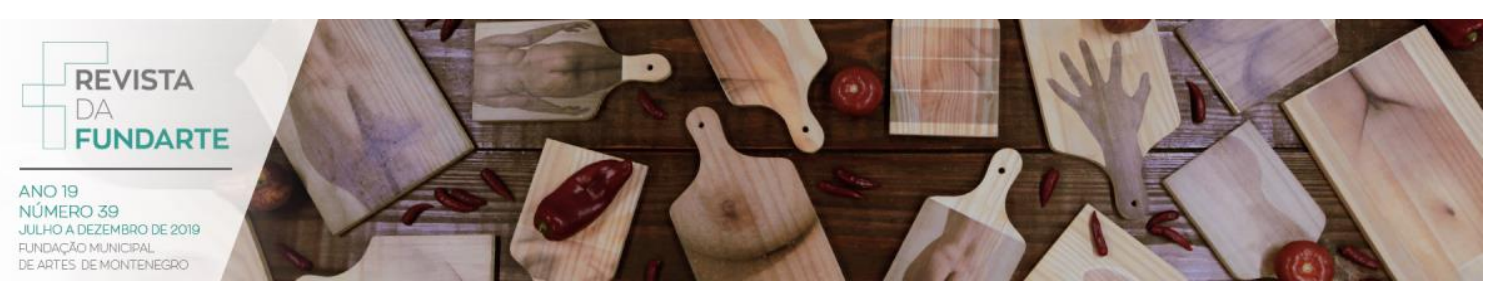

\section{Referências:}

BARBOSA, Ana Mae. Inquietações e mudanças no Ensino da Arte. 2. ed. São Paulo: Cortez, 2003.

CAFÉ, Barcelos Angela. O Contador de Histórias no Ensino do Teatro. O Teatro e suas Pedagogias: Práticas e Reflexões. Brasília: Editora da Universidade de Brasília. 2016.

FERREIRA, Taís. A pedagogia do Teatro e a Recepção Teatral podem caminhar juntas? Os Lugares da Arte. Pelotas: Editora e Gráfica Universitária. 2010.

KOUDELA, Ingrid. A ida ao teatro. Sistema Cultura é currículo, s./d. Disponível em: <http://culturaecurriculo.fde.sp.gov.br/Escola\%20em\%20Cena/>. Acesso em: 11 jul. 2018.

PAVIS, Patrice. Dicionário de Teatro - São Paulo: Perspectiva, 2015.

RYNGAERT, Jean-Pierre. Jogar, Representar. São Paulo: Cosac Naify, 2009.

SOUZA, Luiz Fernando de. Um palco Para o Conto de Fadas: Uma Experiência Teatral com Crianças Pequenas. Porto Alegre: Editora Mediação, 2008. pequenas? Relato de uma experiência vivida como estagiário no curso de teatro-licenciatura. Revista da FUNDARTE, Montenegro, p.209-221, ano 19, no 39, julho/dezembro de 2019.

Disponível em: http://.seer.fundarte.rs.gov.br/index.php/RevistadaFundarte/index $>20$ de dezembro de 2019. 